\title{
Fourth industrial revolution, digital servitization and relationship quality in Italian B2B manufacturing firms. An exploratory study
}

\author{
Roberto Grandinetti
}

Department of Economics and Management, University of Padova, Padova, Italy

Maria Vincenza Ciasullo

Department of Management and Innovation Systems, University of Salerno, Fisciano, Italy and

Department of Management, University of Isfahan, Isfahan, Iran

Marco Paiola

Department of Economics and Management, University of Padova, Padova, Italy, and

Francesco Schiavone

Department of Management Studies and Quantitative Methods,

University of Naples-Parthenope, Napoli, Italy and

Department of Strategy and Management, Paris School of Business,

Paris, France

\begin{abstract}
Purpose - Industry 4.0 is dramatically affecting businesses behaviours and strategies, transforming products design, manufacture, operations and services. An outcome of this transformation is digital servitization. This paper aims to contribute to the extant literature about digital servitization in B2B contexts by analysing how I4.0-based servitization affects the quality of supplier-customer relationships.

Design/methodology/approach - The authors adopted a qualitative methodology based on an exploratory multiple case study. In particular, the study included 22 Italian B2B manufacturing firms whose I4.0-based digital servitization approaches are described and, then, analysed in relation to the quality of suppliercustomer relationships.

Findings - The access to customers and data is critical to enable advanced digital services and for improving relationship quality; the levels of relational intimacy and informational openness lead to two subsequent levels of data-driven efficiency and data-driven effectiveness, impacting significantly on relationship quality and enabling relational innovation.

Originality/value - The research explores the link, so far underestimated, between digital servitization and relationship quality in industrial contexts.
\end{abstract}

Keywords Industry 4.0, Digital servitization, Relationship quality, B2B manufacturing firms

Paper type Research paper

(C) Roberto Grandinett, Maria Vincenza Ciasullo, Marco Paiola and Francesco Schiavone. Published by Emerald Publishing Limited. This article is published under the Creative Commons Attribution (CC BY 4.0) licence. Anyone may reproduce, distribute, translate and create derivative works of this article (for both commercial and non-commercial purposes), subject to full attribution to the original publication and authors. The full terms of this licence may be seen at http://creativecommons.org/licences/by/4.0/ legalcode

Digital servitization in B2B firms

Received 10 January 2020 Revised 20 March 2020 Accepted 28 April 2020 
TQM

32,4

648

\section{Introduction}

Over the past decade, an increasing amount of articles in operations and supply chain management literature focussed on the set of technologies - IoT (Internet of things), cloud platforms, big data (BD) and data analysis (DA) - of the so-called Fourth Industrial Revolution (Industry 4.0, I4.0) (Frank et al., 2019; Schmidt and Wagner, 2019; Gunasekaran et al., 2019). I4.0 refers to "new industrial maturity stage of product firms, based on the connectivity provided by the industrial Internet of things, where the companies' products and process are interconnected and integrated to achieve higher value for both customers and the companies' internal processes" (Frank et al., 2019, p. 343). I4.0 is transforming business market landscapes, offering firms the possibility to monitor, optimize and automatize product's functions, remotely and globally (Liao et al., 2017). These technologies are the core driver of a radical transformation of manufacturing, changing firms' processes and business models via the expansion of service innovation opportunities (Martín-Peña et al., 2018; Kohtamäki et al., 2019; Bustinza et al., 2019).

The widespread of I4.0 technologies supports servitization, that is, "the process where firms set out to create greater value by increasing the services they offer" (Vendrell-Herrero et al., 2017, p. 71). In particular, it triggers a I4.0-based servitization, a strategic approach for achieving market differentiation and increasing the firm competitiveness leveraging on new technologies that literature has named "Digital Servitization" (Coreyen et al., 2017; Sklyar et al., 2019). Such approach, which can take place via the combination of different levels of servitization and digitalization (Frank et al., 2019), greatly affects corporate performances (Kohtamäki et al., 2019) and manufacturing firms' business models (Paiola and Gebauer, 2020). Prior literature reports that digital servitization, moreover, transforms the business ecosystem (Sklyar et al., 2019), its supply chains and business relationships, as occurred in the publishing industry (Vendrell-Herrero et al., 2017). In I4.0-based digital servitization, therefore, the value creation of the supplier depends on its ability to lead its customer to the success (Rymaszewska et al., 2017) by offering value-added services via a variety of digital and customer-oriented business models (Martín-Peña et al., 2018; Kohtamäki et al., 2019; Paiola and Gebauer, 2020).

Despite these evidences, so far the scholars of this stream of literature only sporadically analysed, as explicitly reported by Kohtamäki et al. (2019) in one of their suggested research directions, how digital servitization transforms collaboration in industrial servitization ecosystems. In particular, a neglected but relevant point deserving attention is the quality of the relationship between supplier and customer, a well-known and established concept in industrial marketing literature (Ulaga and Eggert, 2006; Athanasopoulou, 2009). Nowadays high-quality relationships between supplier and customer are crucial drivers of competitiveness that manufacturing firms can leverage and exploit via Internet and digital technologies (Gaiardelli et al.,2014). However, it remains unclear if the mechanisms lead to high quality of the collaboration between industrial manufacturing firms' change across the various forms, business models and applications of digital servitization (Kohtamäki et al., 2019; Frank, 2019).

Drawing on such assumptions, the present explorative article contributes to the extant literature about digital servitization in industrial contexts (Vendrell-Herrero et al., 2017; Rymaszewska et al., 2017; Gunasekaran et al., 2019; Frank et al., 2019; Kohtamäki et al., 2020) by answering the following research question: how do the various forms of I4.0-based digital servitization improve the quality of B2B supplier-customer relationships? The study reports the findings of an exploratory qualitative investigation of 22 Italian industrial manufacturing firms, whose I4.0-based digital servitization approaches are described and analysed in relation to the quality of supplier-customer relationships. The findings suggest that access to customers and data is critical to enable advanced digital services and for improving relationship quality; the levels of relational intimacy and informational openness lead to two subsequent levels of data-driven efficiency and data-driven effectiveness, impacting significantly on relationship quality and enabling relational innovation. The article is organized as follows: Section 2 reviews the main theoretical concepts of the study and offers 
three main theoretical speculations. Section 3 describes the research design and method. Section 4 presents the study findings. Finally, drawing on such findings, Section 5 discusses the results, offers three research propositions and provides various theoretical and managerial implications as well as the limitations of the study.

\section{Theoretical background}

\section{1 (14.0-based) digital servitization}

Over the past years, a number of articles analysed the impact of I4.0 technologies on services and

business relationships of industrial firms (Rymaszewska et al., 2017; Kamp and Parry, 2017). The interplay of sensors and the development of the Internet is central to I4.0: IoT enables data gathering from smart and connected devices, providing firms with strategic information input (Santos et al., 2017). IoT, therefore, is playing a critical role within I4.0 technologies (Arnold et al., 2016). Such past-generation technologies expand dramatically the firms' opportunities for service innovation and, thus, promote servitization by manufacturing firms (Kindström and Kowalkowski, 2014; Baines, 2015). Nowadays, thousands of innovative firms worldwide are increasingly leveraging on I4.0 technologies in order to implement servitization and develop market-service-oriented offerings (Coreynen et al., 2017; Vendrell-Herrero and Wilson, 2017; Baines, 2015). The strong connection between I4.0 technologies and servitization leads, over the last few years, to the rise of the research stream of digital servitization (Vendrell-Herrero and Wilson, 2017; Rymaszewska et al., 2017; Gunasekaran et al., 2019).

Pathways of servitization via I4.0 technologies can take place at value, commercial and industrial levels (Coreyen et al., 2017). Digital servitization is an important lever for differentiation strategy and generates relevant implications for the firm' relationships with its business ecosystem (Sklyar et al., 2019) and performance. For instance, digital servitization in the publishing industry transformed the structure of the supply chain, by separating the infrastructure operation and service provision from production, impacted on vertical B2B relationships (Vendrell-Herrero and Wilson, 2017). Recent empirical researches show the coupled action of digitalization and servitization impacts positively on the sales performance of 828 Spanish industrial firms (Martín-Peña et al., 2020) and the financial performance of 131 Swedish manufacturing companies (Kohtamäki et al., 2020). In addition, advanced digitally based services enable suppliers to initiate and maintain sophisticated process- and outcomeoriented business relationships with their key customers (Paiola and Gebauer, 2020). Among the various corporate capabilities useful to organize and implement digital servitization, agility is found to be crucial for the development of integrated solutions (Bustinza et al., 2019). The design, adaptation and marketing of new smart product-service systems (PSSs) around which to focus on a novel corporate business model is one of main requirements for manufacturing firms in order to achieve effective value innovation within the I4.0 paradigm (Matthyssens, 2019).

Such capabilities are likely to support the adoption by firms of digital business models shifting firms' value propositions gradually away from pure products towards pure customeroriented services (Martín-Peña et al., 2018). Within this context, industrial firms can capture value (Ehret and Wirtz, 2017) by adopting one of the following business models: industrializer, product-oriented service provider, customer-integrated solution provider, platform provider and outcome provider (Kohtamäki et al., 2019). Capital equipment manufacturers that used to achieve profitability from conventional services such as spare parts are, therefore, changing their value propositions and technical composition towards PSSs (Hypko et al., 2010), and looking at such new revenue models (Rymaszewska et al., 2017). IoT-based, customer-oriented and outcome-oriented PSSs imply a radical shift in the fundamental revenue models of the firms, introducing usage-based, performance-based and value-based revenue models (Adrodegari and Saccani, 2017). This shift changes the mechanisms of revenue generation (along with costing structures, risk assessment and reciprocal liabilities among partners) from a 
TQM

32,4

transactional perspective to a relationship-based one (Gaiardelli et al., 2014). Finally, firms can implement digital servitization by combining different levels of servitization and digitalization. Only if both are implemented at maximum levels, the supplier is able to offer process- and customer-oriented added-value solutions to its customers (Paiola and Gebauer, 2020).

\subsection{Relationship quality and digital servitization in B2B markets}

Scholars in industrial marketing literature proposed various configurations for the concept of relationship quality between supplier and customer. This dynamic concept links together several elements such as service quality, customer satisfaction, relationship strength, relationship longevity and relationship profitability (Storbacka et al., 1994). Many authors report that the key antecedents of the construct are trust, commitment and satisfaction (Morgan and Hunt, 1994; Ulaga and Eggert, 2006). Other elements that affect relationship quality are conflict, cooperation, opportunism, power, adaptation, atmosphere and bonds (Athanasopoulou, 2009). More recently, relationship quality was classified as a higher-order construct based on communication, long-term orientation, social satisfaction and economic satisfaction (Jiang et al., 2016). Referring to profitable outcomes, Huntley (2006) found that willingness to recommend, product sales, services sales are also relevant measures in order to assess the quality of an industrial relationship. Relational benefits, such as anticipation of future interaction or customer loyalty, are also valid outcomes of the quality of B2B relationships (Athanasopoulou, 2009).

More empirical studies in B2B and strategy literature show that digital servitization offers great opportunities for improving the quality (and changing the dynamics) of the relationship between supplier and customer in industrial markets. Digitization provides better resources allocation, efficient operations and improves service quality via information sharing within the B2B network (Kindström and Kowalkowski, 2014). The provision of digital services via cloud technology (eBooks) was the core of servitization in the publishing industry which increased the dependence between suppliers and customers (Vendrell-Herrero et al., 2017). Counting on hundreds or thousands of smart and connected devices installed at the premises of final-user firms provides space for brand new and personalized data-based serviceoriented and customer-oriented offerings (Porter and Heppelmann, 2014). The exploitation of IoT was found crucial for the development, implementation and success of relationship marketing strategies in a very heterogeneous set of industrial contexts, such as the camping industry or the power thermal management (Lo and Campos, 2018).

Despite such indirect but promising evidences from other research streams, scholars in the field of operations management paid only marginal attention to the link between I4.0-based servitization and the quality of supplier-customer relationship. For instance, in their exploratory qualitative study, Rymaszewska and her co-authors (2017) report the that support to customer success, which indirectly augments also the relationship quality between partners, is a central element of the value creation achieved by the supplier via IoT-based servitization. Digital technologies for servitization can be exploited, at a basic level, in order to support and make some manual activities more efficient, as happens for the management of CRM software and the creation of customers' databases (Frank et al., 2019). Servitization, usually powered by IoT, intensifies the strength and thus also the quality of relationships between manufacturers and customers. Indeed, industrial firms need to increase their commitment (e.g. investments) and cooperation in order to make the partnership successful (Baines, 2015). Recent research acknowledges that IoT-based industrial domains are perfect research settings for the so-called co-created servitization (Green et al., 2017), a value-creating approach which lies on the service-dominant (S-D) logic (Vargo and Lusch, 2008) and, basically, empathizes all the key underpinnings of the concept of relationship quality (e.g., commitment, trust) between supplier and customer. 


\section{Research method and design}

With I4.0-based servitization being still an emerging and complex phenomenon, coherently with well-known specific literature on qualitative research and collective case study (Eisenhardt, 1989; Yin, 1994; Stake, 1995), an explorative qualitative investigation with a cross-analysis of different companies was implemented in this research. The aim of the empirical analysis was to investigate the impact of I4.0-based digital servitization on supplier-customer relationships in B2B manufacturing industries. More specifically, we aimed at studying the changes in supplier-customer relationships' fundamental mechanisms and underlying factors (relational focus, required trust, featured commitment and adaptation, cooperation and co-creation intensity and overall cost and benefit sharing agreements) brought about by the introduction of new service-oriented value propositions enabled by I4.0 technologies such as IoT, cloud platforms, BD and DA.

Accordingly, the focus is on diversity instead of aiming at building a statistically representative sample, designing a setting able to describe the different situations and challenges facing firms in leveraging I4.0 technologies for servitization (Miles and Huberman, 1994).

The research approach is a multi-step one. In a first investigation phase, ten industry experts were selected on the basis of their specialization in the field and their expertise - using secondary data, personal and professional contacts - and interviewed through the use of a semi-structured interview template. Indications and suggestions coming from this preliminary phase have been critical in identifying and listing the initial group of firms to be investigated. Moreover, secondary information has been gathered in order to identify and screen firms' strategies and initiatives connected to I4.0 technologies and in particular IoT technologies.

The following criteria were used to select the cases for the research project. They had to: be B2B manufacturing companies headquartered in Italy; have at least one project related to Io $\mathrm{T}$ technologies ongoing for more than one year; recognize the importance of the research activity and commit in it; be willing to collaborate and provide access to information and knowledgeable informants. Research interviews took place from the end of 2017 throughout 2018: in-depth analysis of gathered data conducted by us to exclude some of the analysed firms for not complying with one or more of the aforementioned criteria. Eventually 22 case companies were chosen to be the base of the work described here.

The number of investigated firms is consistent with the sample sizes recommended for exploratory research and used in research protocols for similar investigation (Laudien and Daxbock, 2016: 11 cases; Ulaga and Reinartz, 2011: 22 cases; Ricciardi et al., 2016: 35 cases; Müller et al., 2018: 64 cases). The relatively high number of sampled cases contributes to lower the investigation bias, mitigating the risk of selecting companies with distinguishing abilities or inabilities towards I4.0 (Müller et al., 2018).

C-level managers belonging to the different case companies were contacted, targeting both top managers (CEOs, and GMs) and specific function managers presumably directly involved in the transformation driven by I4.0 (such as CTOs, CIOs, etc.). An introductive phone call by the researchers to the interviewees was made in order to explain the nature and aims of the research, to assess the actual firm's willingness to participate in the investigation and to identify which managers and other positions were specifically to be involved in the interviews. Then, data was collected by in-depth face-to-face semi-structured interviews with firms' key informants and top managers in charge of activities heavily impacted by I4.0related technologies. In many cases, two or more people have been involved in the interviews, for a total duration of approximately $51.5 \mathrm{~h}$. Table 1 portraits an outline of the sample: the total number of interview sessions, the roles of the interviewees, the total duration of the interviews per company.

Interviews were registered, transcribed, categorized and coded following proper methodological procedures (Voss et al., 2002), in order to better understand the differences servitization in B2B firms 


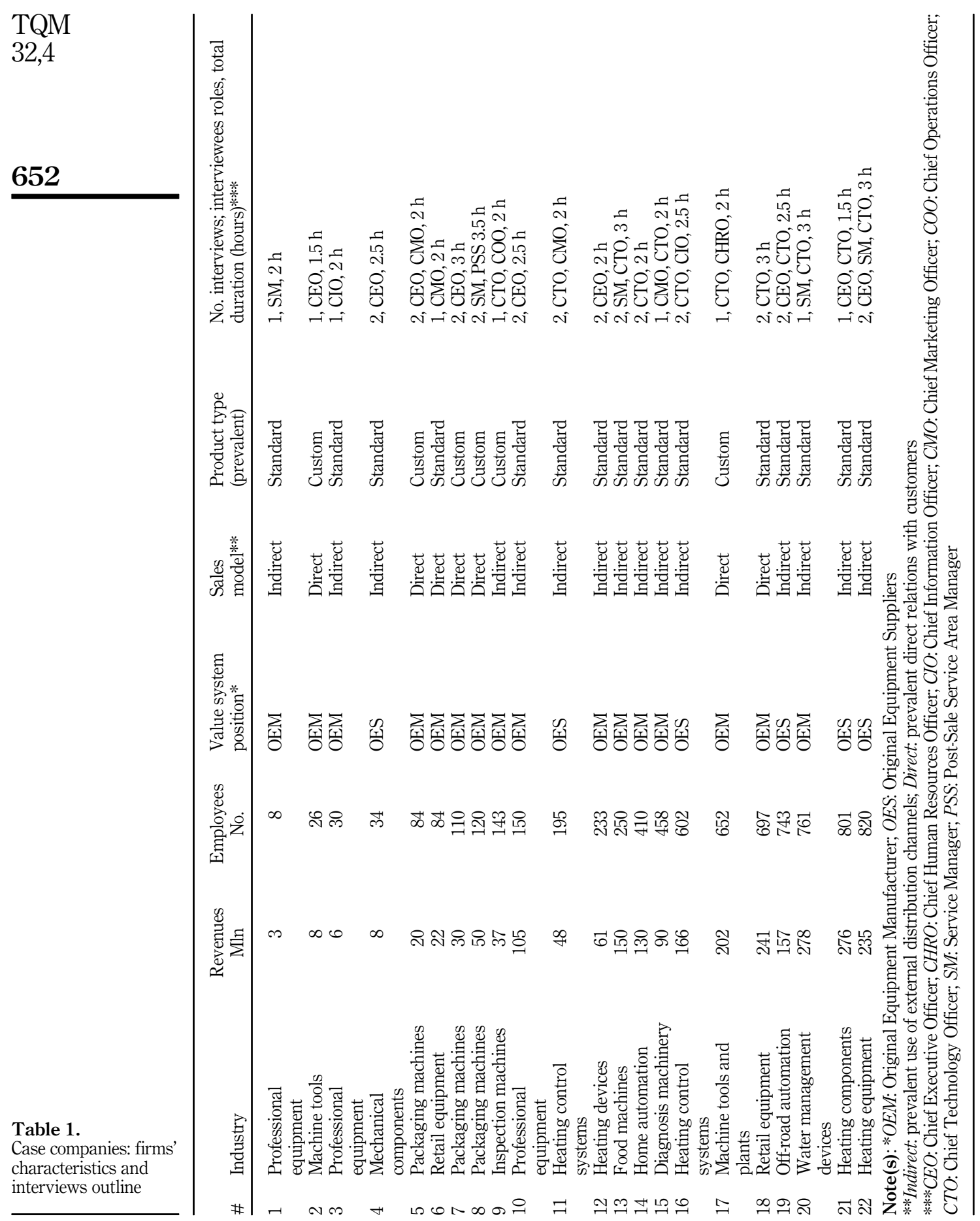


and similarities among the cases (see Appendix for the Data Structure). Data triangulation was deployed with the aim to minimize contextual bias and maximize data reliability (Yin, 1994). Follow-up meetings and calls have been arranged in order to deal with any unclear topic and avoid any misinterpretation. Main results of the investigation have been shared with interviewees in the form of a detailed presentation of the findings in order to have a first and direct feedback regarding the accuracy of the data.

All the firms are located in the North of Italy (in particular in the regions: Emilia Romagna, Friuli, Lombardy, Veneto). Being the most advanced industrial regional system in the country and one of the most relevant in EU, this geographical location boasts a long and acknowledged tradition and a world-class standing in terms of manufacturing production (De Marchi and Grandinetti, 2017).

As Table 1 shows, the sampled firms cover various industrial specializations that are heavily involved in technological evolutions related to I4.0, such as the manufacturing of: machine tools and plants, mechanical components, packaging machines, food processing machines, inspection and diagnosis machines, water management devices, professional cooking equipment, retail equipment, heating control systems and devices, off-road automation devices.

The case companies have different positions in the value system and adopt different sales models: 16 of them are original equipment manufacturers (OEMs) and six original equipment suppliers (OESs), while seven firms sell prevalently directly to their final-user firms, and 15 have a mainly indirect access to the customers. One firm is very small (below 20 employees), whether a core group of 14 enterprises are SMEs, employing a range of 20-250 people (European Commission 2003/361/CE). A final group of seven firms are medium-to-large enterprises, with a total number of employees above 500. Similarly to Laudien and Daxböck (2016), no large multinational corporation has been included in the investigation, and no firm in the sample has more than 1,000 employees.

The case companies frequently focus their competitive strategies on specific segments or niches, with a consequent specialization of resources, capabilities, products and services: standard products are mainly produced in low- to medium-sized batches, and six firms prevalently customize their products and solutions on customer's needs. Very often, firms are leaders in the respective niche/industry, testifying for a tradition of good managerial capabilities and successful strategic alignment with the environment so far. Nonetheless, they are looking at the present technological transformation with great attention and caution, aware of both the opportunities and threats it presents.

\section{Case study analysis}

\subsection{Main findings}

Table 2 summarizes the main effects of I4.0 technologies on firms' servitization and customers' relations.

On the whole, we register that all the firms in the sample have invested in I4.0 technologies for their products (in order to make them smart and connected) but not in every case the digitalization is complete: the effects on supplier-customer relationships are therefore differing in intensity and extension from case to case.

In fact, while the presence of IoT devices is thorough and Cloud computing systems are almost as much frequently adopted, only 11 firms have deployed solutions that involve DA and only three of them can leverage on BD. In addition, the real utilization of the available technological outfit for providing services may vary significantly from firm to firm, and only in very few cases I4.0-based services have produced radical changes in the relationships with customers: in fact, in most instances (18 out of 22), the use of I4.0 technologies for services provided and the fundamental relationship factors aforementioned are limited or incremental. This evidence is in line with other similar studies (see e.g. Muller et al., 2018). 
TQM
32,4

654

Table 2.

I4.0 technologies, digital servitization and relational effects in the sampled firms

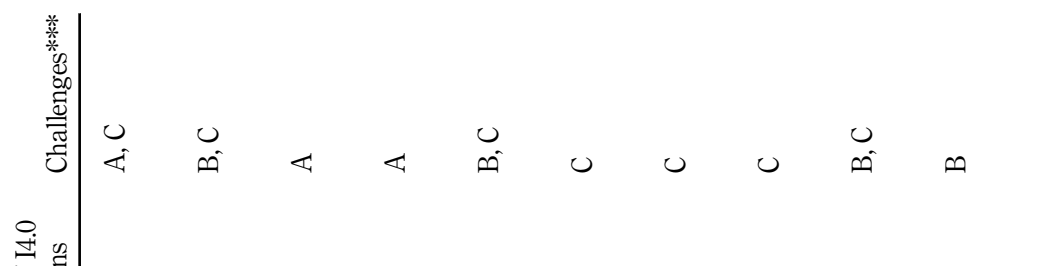

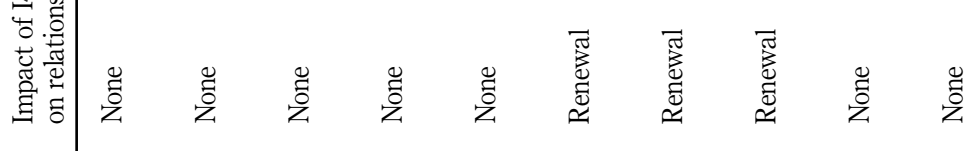

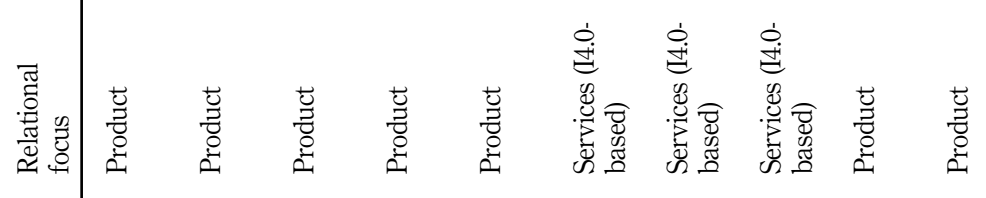

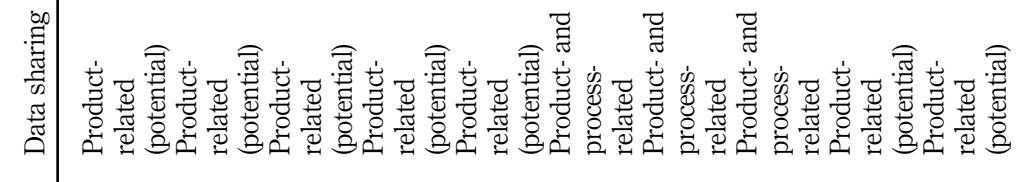

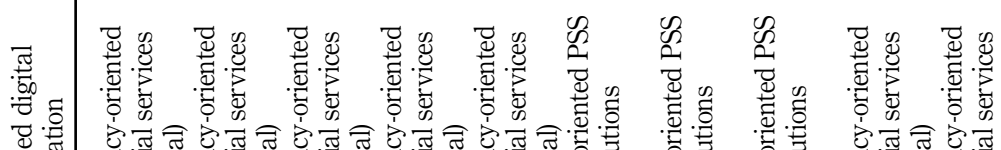

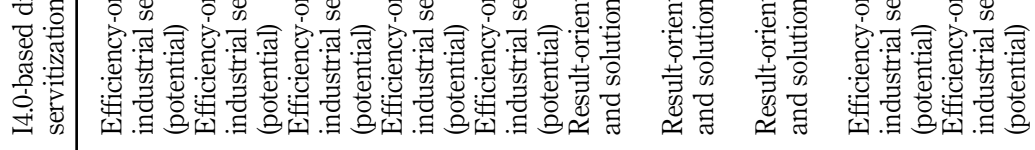

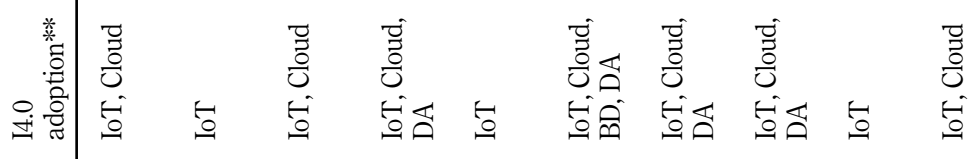

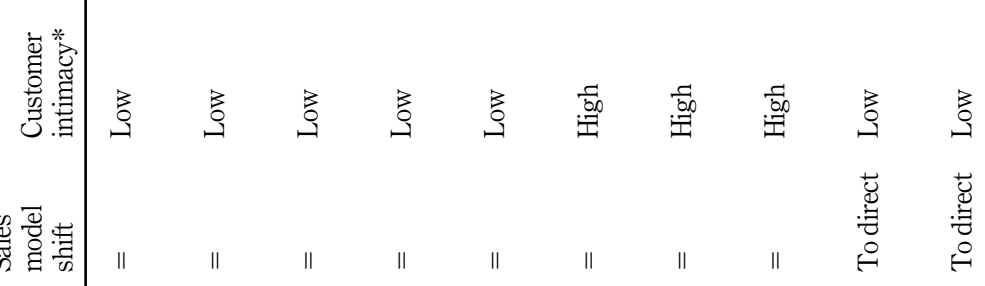

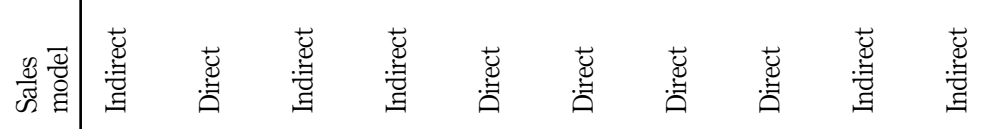

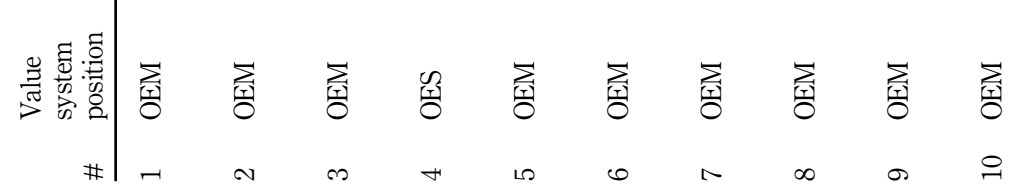




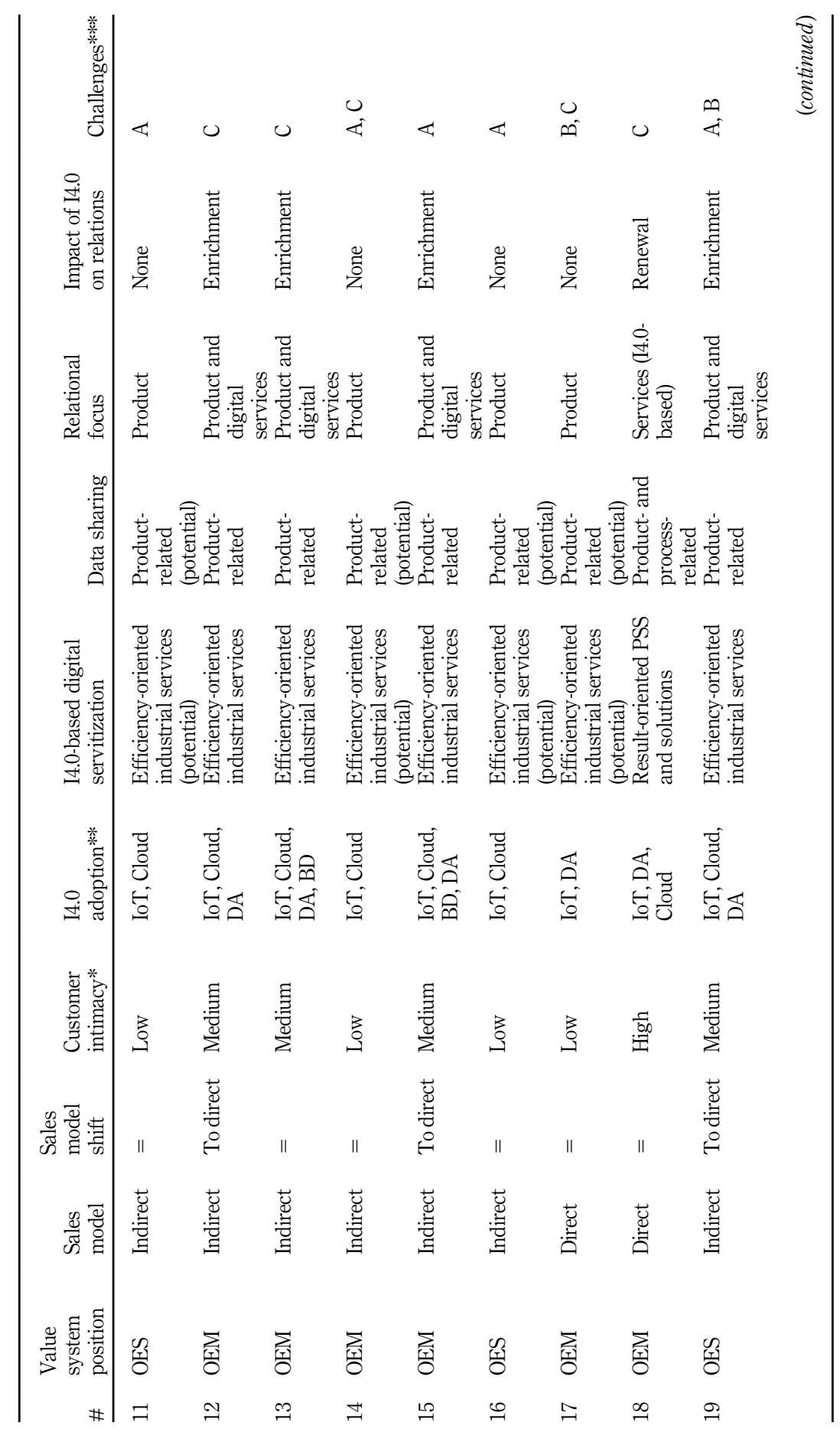

Digital servitization in

B2B firms

655

Table 2. 


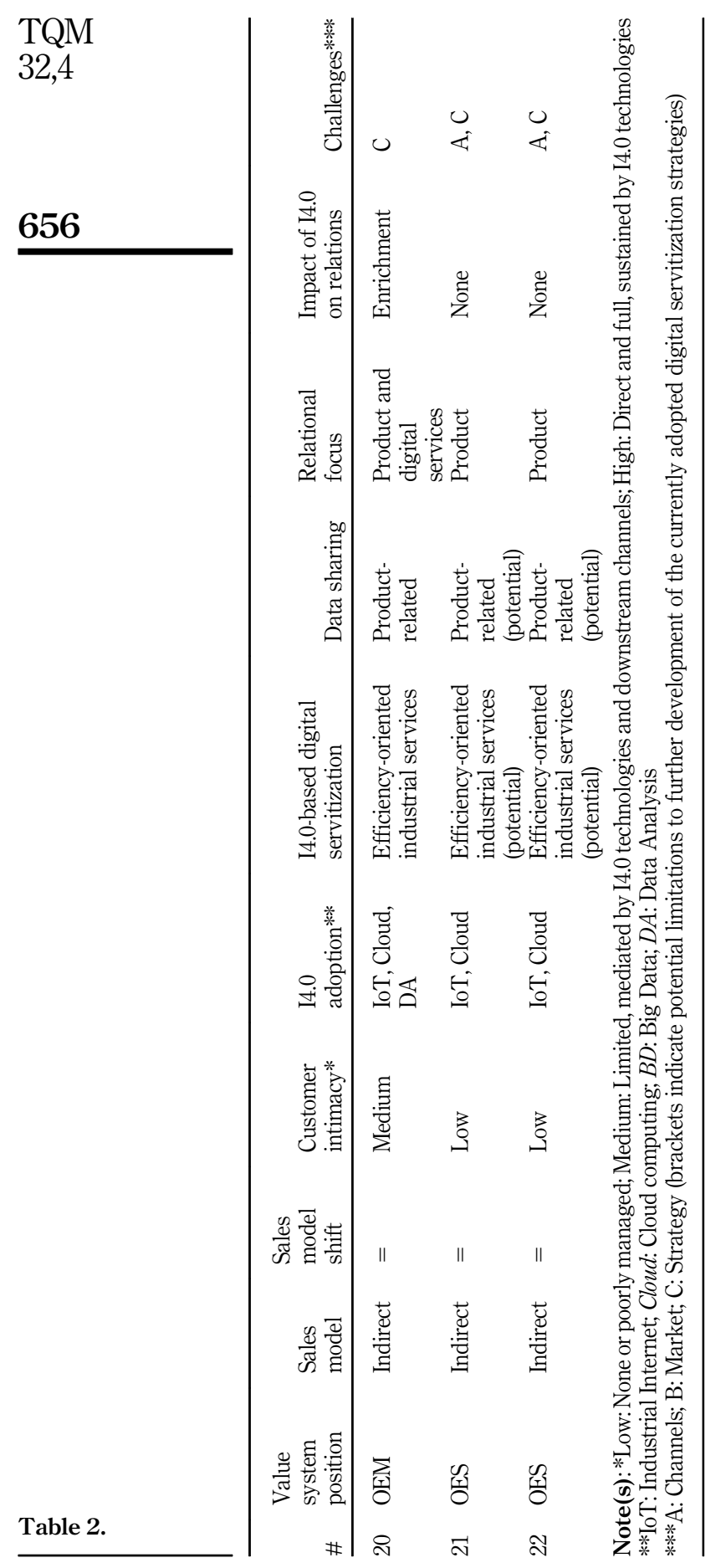


The manifold picture depicted by our findings can be usefully schematized by three levels of impact of I4.0-based digital servitization on business relationships. A first basic level is related to 13 firms that are currently not able to realize the service potential of the technologies, showing trivial impact on relations with customers. An intermediate level regards other firms (five in total) that have been able to leverage I4.0 technologies in order to enrich their products with platform-based digital services; these firms use the data generated by their installed base to streamline asset efficiency and to upgrade customers' relations. A third level is related to firms (four in total) for which I4.0 technologies are enabling new digital services that are completely renewing the relation with customers. The following subsections will describe the mechanisms of the relationship quality improvement for each level.

\subsection{Theoretical speculations}

At this stage, at least three theoretical speculations can be developed about the impact of the various forms of digital servitization on the quality of supplier-customer relationships between manufacturing firms. First, I4.0-based servitization generates value for the supplier by contributing to the success of the customer (Rymaszewska et al., 2017). The outcome of this achievement is a very likely positive impact on the overall relationship quality (Huntley, 2006). Prior literature reports that digital servitization should lead to successful new services for customers only if the supplier is an agile company (Bustinza et al., 2018). However, agility is likely to be particularly relevant not only for manufacturing personalized integrated solutions but also for building high-quality relationships. Indeed, this corporate capability should be likely to increase the supplier-specific commitment in the transaction and its adaptation to the customer needs (Athanasopoulou, 2009). In brief, I4.0-based servitization can truly improve the relationship quality only if the supplier digital business model promotes and emphasizes its agility capability for managing both internal (manufacturing) operations and external relationships with customers (mediating role of agility).

Second, the rich amount of data provided by I4.0 technologies, such as blockchain and edge computing, is potentially a great driver of trust between customers and suppliers since it allows continuous information sharing, transparency and accountability about, for instance, supply chain operations and contracts (Iansiti and Lakhani, 2017; Li et al., 2018). The availability of data via such technologies should also decrease information asymmetry and opportunism (Schmidt and Wagner, 2019) and, thus, is likely to lead both the parties to increase their commitment in the relationship. In other words, the positive impact offered by digital servitization is likely to be twofold. At competition level, this process generates market differentiation and makes the firm more competitive. At relationship level, only those forms of I4.0-based servitization built on data transparency and accountability can truly make easier the development of reciprocal trust and commitment among the parties and, thus, increase relationship quality (mediating role of trust).

Third, prior literature reports that the outcomes of industrial relationships can be transactional and/or relational (Huntley, 2006; Athanasopoulou, 2009). Therefore, digital servitization can lead to the maximum success for the parties and improve the relationship quality only if both the outcomes and benefits are achieved by both the parties. This twofold achievement is extremely important for companies operating in a technological paradigm as I4.0, in which relationship-based approaches substitute traditional transactional approaches (Gaiardelli et al., 2014) and phenomena as open manufacturing (Li et al., 2018) create networks of customers in continuous interaction with networks of manufacturers. Therefore, a relevant improvement of the relationship quality via I4.0-based servitization should be achieved only if the supplier business model is intendedly designed for marketing PSSs able to offer tangible and intangible (relational) benefits to both the parties (mediating role of benefits sharing).

4.2.1 Level 1: latent digital servitization and latent effects on relationships. The effects that I4.0 may have on services and supplier-customer relationships are at first related to the use of 
TQM

32,4

data for sustaining the installed base efficiency, using digital devices that make products smarter. Although technologically feasible for every firm, for the majority of the sampled firms this outcome remains latent due to the action of several contingent and firm-specific factors that limit customer intimacy, such as: the downstream channels, the features of the market and the customers and the firm's organizational and strategic culture (see Table 2). This condition of having none or poor market relations regards an overall group of 13 cases (out of 22) of which eight are OEMs and five OESs.

First, the position in the value chain and the sales model may simply prevent a direct relation to final-user firms and their data: 10 of these 13 companies have an indirect sales model (see cases 1, 3, 4, 9, 10,11, 14, 16, 21, 22 in Table 2 and in particular challenge A), and five OESs (out of six) are in this group. Here, downstream channels - the articulated structure of intermediating actors between the firm and the market - play a critical role in hindering manufacturers' digital servitization strategies. Distribution channels' focus chiefly on logistical operations efficiency and the lack of service culture may be obstacle to manufacturers' willingness to add services and compose a complex offer for the end-user firm. In relation to this, Company 3's Marketing Officer said:

... Our value system is so articulated and complicated and we are simply too little to be relevant for distributors and to be seen by end-user firms.

As a consequence, three of those ten firms (overall five firms out of a total of 15 firms with an indirect sales model) have initiated to change their positioning in the value system (see Table 2: Sales model shift "to direct"), in order to improve their relational intimacy with customers. However, getting closer to the market with these downstream re-positioning moves is neither easy nor rapid, and it may challenge firms' manufacturing and service culture (only one out of six of those moves are by suppliers). For instance, company 12's CEO said:

Since the distribution channel has always been our market, the perspective of a direct contact with the end-user firms appeared in the first place as a threat for our identity as a manufacturer.

In addition, customers may not be prepared to fully leverage the new technological possibilities (see challenge B in Table 2: cases 2, 5, 9, 10, 17). In some cases, I4.0-based servitization - although technologically and organizationally completely viable - is in a stand-by status due to the weak reaction of the market that is not ready for a full use of I4.0. In this regard, company 2's CEO said:

... Customers simply are not interested in the new applications and services.

In other cases, digital servitization is prevented by the low average rate of utilization of the products by the end-user firms. In this direction, company 10's CEO claimed:

Analyzing the data related to our installed base, we have discovered that owner-operated businesses have a very low rate of utilization ... it discourages us to invest in any solution aimed at supporting their processes or introducing advanced PSS.

Finally, the difficulties encountered by the firms may be related to organizational and strategic culture limitations: findings show that smaller firms with limited resource slack and limited digital capabilities, together with large and specialized suppliers (OESs) with traditional manufacturing culture, are conscious of the need to refresh their organizational and strategic resources and to invest in I4.0-related capabilities (see challenge $\mathrm{C}$ in Table 2: cases $1,2,5,9,14,17,21,22)$.

4.2.2 Level 2: 14.0-based efficiency-oriented industrial services enrich relationships. A more effective use of I4.0 technologies implies the provision of an initial form of digital servitization with services embedded in a platform solution (see Table 2: cases 12, 13, 15, 19, 20). 
This second level requires the adoption of a rather complete technological outfit (IoT, Cloud, DA and less frequently BD) and the design of platform services that use data coming from the installed base to provide automated product-related digital services aimed at increasing the control over products' operating conditions. In all the sampled cases pertaining to this level, the digital service is sold in the platform as a service (PAAS) form that is with a monthly feebased monetization model.

A series of circumstances have to be underlined in order to describe in detail the enrichment of relationships' quality that is in place here. First, the addition of platform-based digital services to otherwise traditional products via smart devices induces an extension of manufacturers' typical transaction-based relational focus: in fact, in these cases a new service-oriented ingredient is stuck onto the product, eliciting a specific attention to digital services strictly related to condition monitoring data. The relational focus between supplier and customer shifts from the product to "product and (digital) services".

Furthermore, specifically related to the aforementioned circumstance, a significant data sharing activity is going on in these supplier-customer relationships, involving the information relevant for monitoring the supplied product's (machinery, equipment and systems) conditions. Technically, digital servitization rests on IoT devices installed on the machines (such as original equipment IoT devices or retrofitting connection kits), cloud or proprietary repositories and appropriate analytic engines that enable real-time monitoring on both the supplier and the customer sides and allow improvements of some product life cycle services such as maintenance ticketing and warranty management. Ultimately, these digital services are extensions of basic product's functions and are oriented towards an increase of the efficiency of the product itself, helping resource allocation optimization, operations efficiency and overall maintenance costs on the customer's side. On the supplier's side, these new features aim both at further differentiating the product and increasing customers' loyalty and at reducing the costs associated to necessary or even mandatory installed base life cycle services. As company 20's CTO said:

We have been the first in our industry to realize that having an excellent product ... as we already have ... is not enough anymore, and to leverage on digital technologies for enriching and expanding the functions of the products, increasing at the same time the loyalty of distributors, technical partners and final users ....

All of this has interesting effects on the quality of supplier-customer relationship. As detailed in Table 3, I4.0-based service platforms allow firms to increase customer intimacy to a level that is easily manageable through standardized digital communication systems. A relevant part of the supplier-customer relationship data flow is mediated by I4.0 technologies and therefore highly standardized and scalable.

Notwithstanding the inherent industrial approach in data sharing and relational management, trust is an important factor. A given level of trust is, in fact, needed for having the customers' permission to access product-related data, memorize and analyse them in order to input the platform's software and generate distributed condition monitoring updates. It is obviously a trust component that goes beyond the overall trust that the customer places in the manufacturer as supplier of reliable machines and equipment, and it is related to the trustworthiness of the supplier to guarantee the integrity and security of every single customer's data throughout and beyond the product's life cycle.

Our findings show that for digital platform services to work well, a limited but critical level of commitment and adaptation by both the parties involved is needed. Digital platforms are designed to be "general purpose" from the outset (in relation to the given product or product line supplied) and if the design phase has been carried out properly, most popular customer needs are targeted by the platform's active or activatable functions (differentiated subscription profiles may be associated to different functional completeness). 
TQM
32,4

660

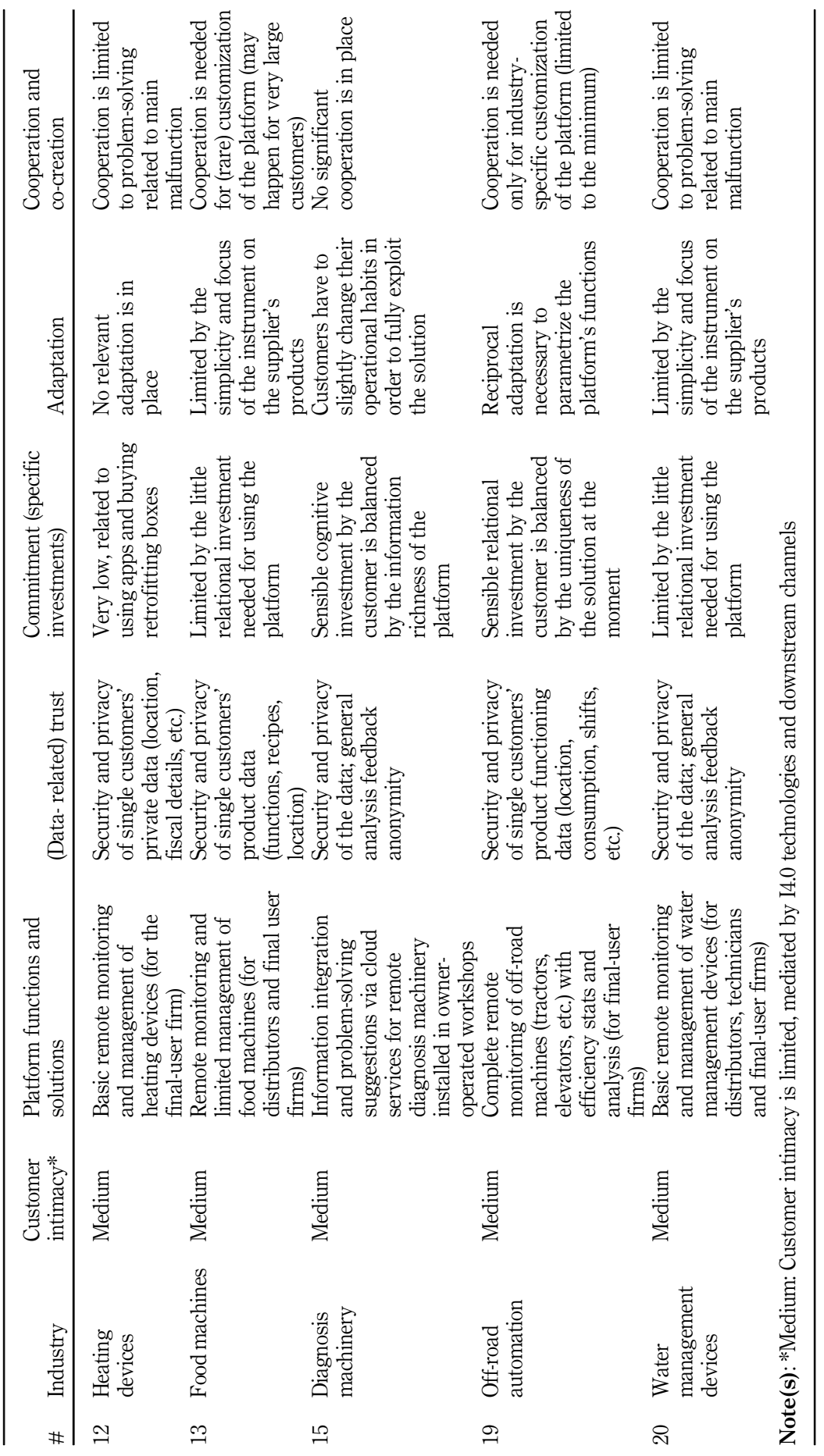

Table 3.

Level 2: I4.0-based efficiency-oriented industrial services (details) 
Nevertheless, a certain level of commitment is necessary to unlock the platform's potentiality and do the initial parameterization and adaptation to the customer's organizational and information systems requirements. Of course, reciprocal commitment and adaptation are comprehensively bounded to the nature and specificity of the machine. Likewise, cooperation activities are limited to sharing organizational and technological details and work together for guaranteeing the platform's standard operation performances, an activity that typically characterize its installation phase and its prospective upgrades.

4.2.3 Level 3: I4.0-based advanced solutions renew business relationships. The use of I4.0 may as well go beyond what described in the preceding section. In fact, in the remaining four firms reported in Table 2, technologies are leveraged for supplying complex services and solutions aimed at sustaining and enhancing customers' processes performances. At this third level, I4.0-based remote equipment monitoring and control capabilities are used to amplify and extend already excellent manufacturers' capabilities in order to initiate and sustain sophisticated experimentations of performance-based contracting (PBC) with key clients.

A significant transformation in supplier-customer relationships is in place here, directly connected to a pervasive and in-depth use of new digital technologies. Indeed, I4.0 technologies act as strategic enablers in this level's digital servitization experimentations, allowing the setting of complex contractual agreements that parametrize products' revenues to the value they effectively generate for the customer. The underlined changes in the traditional business relations do not have to be overlooked: on the one side, these contracts relieve the customer from the risk of not being able to reach the operational outcomes necessary for sustaining their most innovative value creation strategies, in terms of efficiency, flexibility, sustainability and so on. Moreover, at the same time, they put suppliers' revenue models at stake, driving (at least part of) the billing mechanism out of the manufacturing industries' traditional upfront invoicing. In fact, $\mathrm{PBC}$ benchmarks revenues to given agreed-upon equipment's efficiency measures (i.e. uptime level), adopting a risk-andgain sharing approach based on ad hoc and recursively negotiable contractual agreements.

The adoption of a complete technological outfit (IoT, Cloud, BD, DA) is mandatory for this third level of digital servitization (all the firms are accumulating data but only one of them may say to leverage BD at present). Various capabilities of smart and connected products such as remote condition monitoring, remote control, remote optimization and device autonomy - play here a significant role in enabling sophisticated revenue models (such as performance-based contracts) and make them sustainable. At a technological level, while the simplest of those capabilities may be conveniently provided by automated platform services like in level 1 (in particular, remote monitoring and control), unlocking the most advanced features of this level, inherently oriented to process optimization and outcome guarantee, requests customer-specific investments in terms of both organizational and technological resources and capabilities (from dedicated human resources to ad hoc technological infrastructures).

For these reasons, such advanced situations are difficult and scant (see Table 4: cases 6, 7, 8 and 18): these four cases are all OEMs with a custom or modular product and a direct sale model that operate in highly competitive markets facing international and global customers, which frequently are MNEs with sophisticated needs and big bargaining power. Our findings also show that sophisticated customers selected within this context are valuable key users with which the firms can explore the most advanced and complex uses of I4.0 technologies. In this direction, Company 8's Service Manager asserted:

... In this strategic experimentation, together with the customer, we are inventing new services that affect directly the customer's business, and are posing the bases for changing our business as well .... 


\begin{tabular}{l} 
TQM \\
32,4 \\
$\mathbf{6 6 2}$ \\
\hline
\end{tabular}

Table 4.

Level 3: I4.0-based advanced solutions (details)

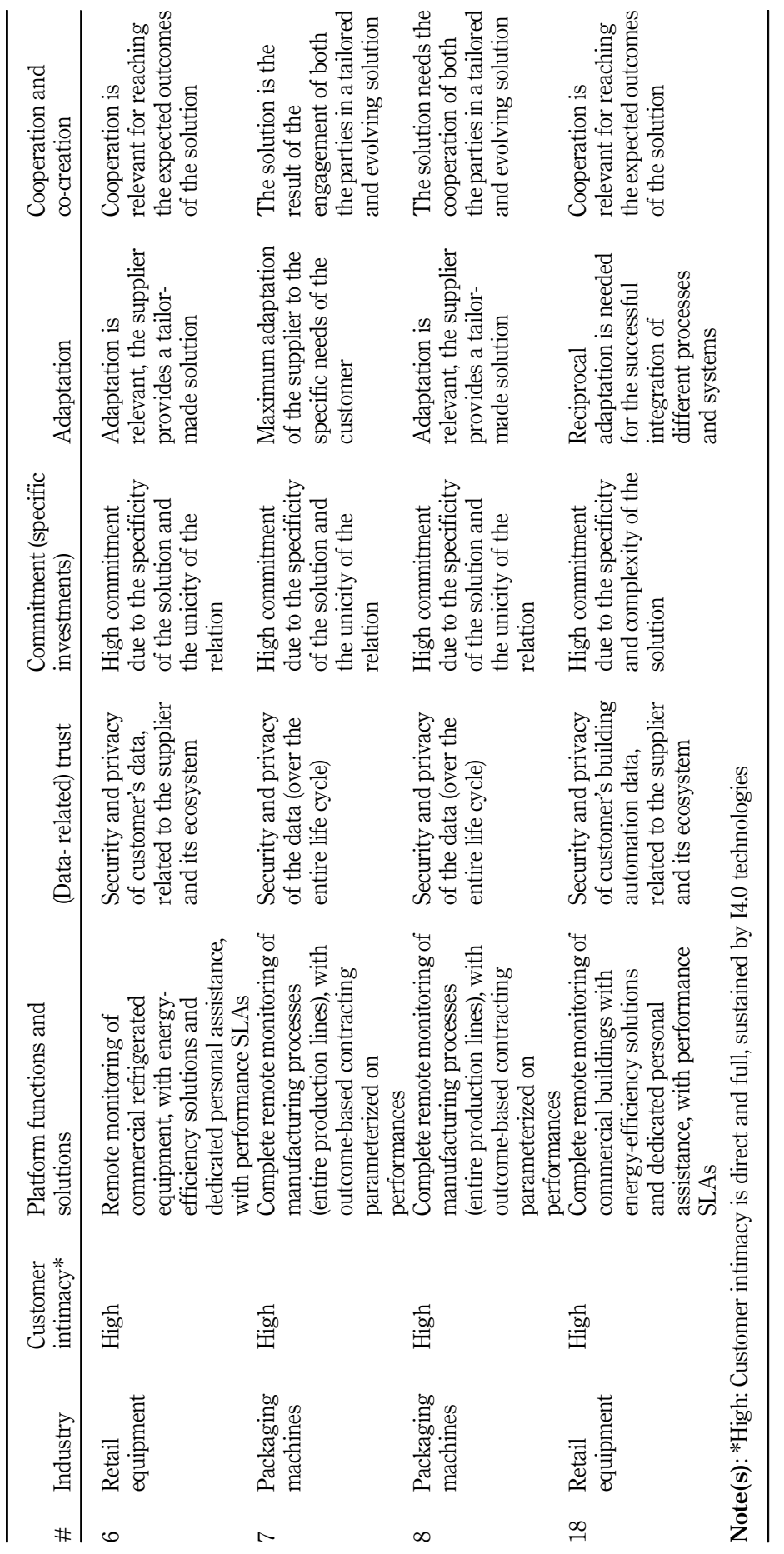


As regards relationship quality, these cases testify for a complete shift of the relational focus from product to (digitally empowered) service, with I4.0 playing as fundamental enabling factor.

The overall effect on supplier-customer relationship quality is pivotal for the success of these complex I4.0-based servitization experiences, starting with data-related trust. In fact, the need to be reputable and reliable in guaranteeing data security for the entire customer's life cycle (already seen in level 2) is here extended to other elements of the value system that participate in the I4.0-based complex solution (encompassing competitors' machines and complementors' products). As far as cybersecurity is concerned, we observe that all the four mentioned firms are using best-in-class security solutions.

As previously mentioned - differently from level 2 - the present level encompasses the implementation of highly personalized and complex product-service solutions. The solutions are extremely complex and co-created: each business relationship entails the articulation of different offerings composed by basic and advanced services (variety), encompassing different products (even competitors' ones) and services (also involving external partners). Moreover, they are inherently tailored to specific needs: this requests to both suppliers and customers - if they aim at ensuring the success of the innovation - to face relevant commitment (relationship-specific investments) and willingness to adapt reciprocally (in terms of culture, language and processes) and to participate in common learning processes (see Table 4 for a summary). Lastly, those elements show a continuous evolution during the relationship over time (variability) that may involve also the benefit sharing mechanisms included in the agreed-upon contracts. Company 18's CTO claimed:

The challenge here is to find the right customer, with which to share the vision, the costs, the uncertainties and also the great potential benefits of developing an advanced service-based solution ... something unique that cannot be bought off-the-shelf in the market ...

\section{Discussion, implications and limitations}

\subsection{Discussion}

This study seeks to shed light on how I4.0-based servitization is affecting manufacturing firms' customer relationship quality. This section discusses the main findings in relation to the extant theory and highlights the key contributions of the study. Drawing on the assumption that multiple business models for digital servitization exist (Kohtamäki et al., 2019, 2020), we propose some ideal characteristics that different types of business models should hold in order to improve the relational quality of supplier-customer relationships.

Firstly, the research testifies that despite the increasing offer of technological solutions and platforms for B2B Cloud solutions, manufacturing firms able to implement and leverage those solutions are still rare. The explanation of this circumstance is twofold: on the one hand, this work makes its own the words of other scholars that stated "fortune favors the prepared" (Müller et al., 2018), underlining the role of a deliberated and proactive strategic approach to make "fortune" with I4.0. On the other hand, the main results of this research sustain other studies' evidence showing that - especially in the most advanced cases - some customers' relationships may be particularly helpful in supporting the company's exploration process (Bednarek et al., 2016; Im and Rai, 2008). In fact, an intense cooperation between suppliers and (key and selected) customers is a fundamental trait of our most advanced cases of I4.0-based servitization. Overall, following and extending the approach adopted in the previous section, it is possible to classify the case companies in three different clusters, as shown in Table 5.

The majority of the sampled firms (13 in total) belongs to a cluster where, at present, I4.0 technologies are used solely in pre-sales services in order to support sales force activities, 


\section{TQM \\ 32,4}

\section{4}

Table 5.

The effect of I4.0 technologies on supplier-customer relationships

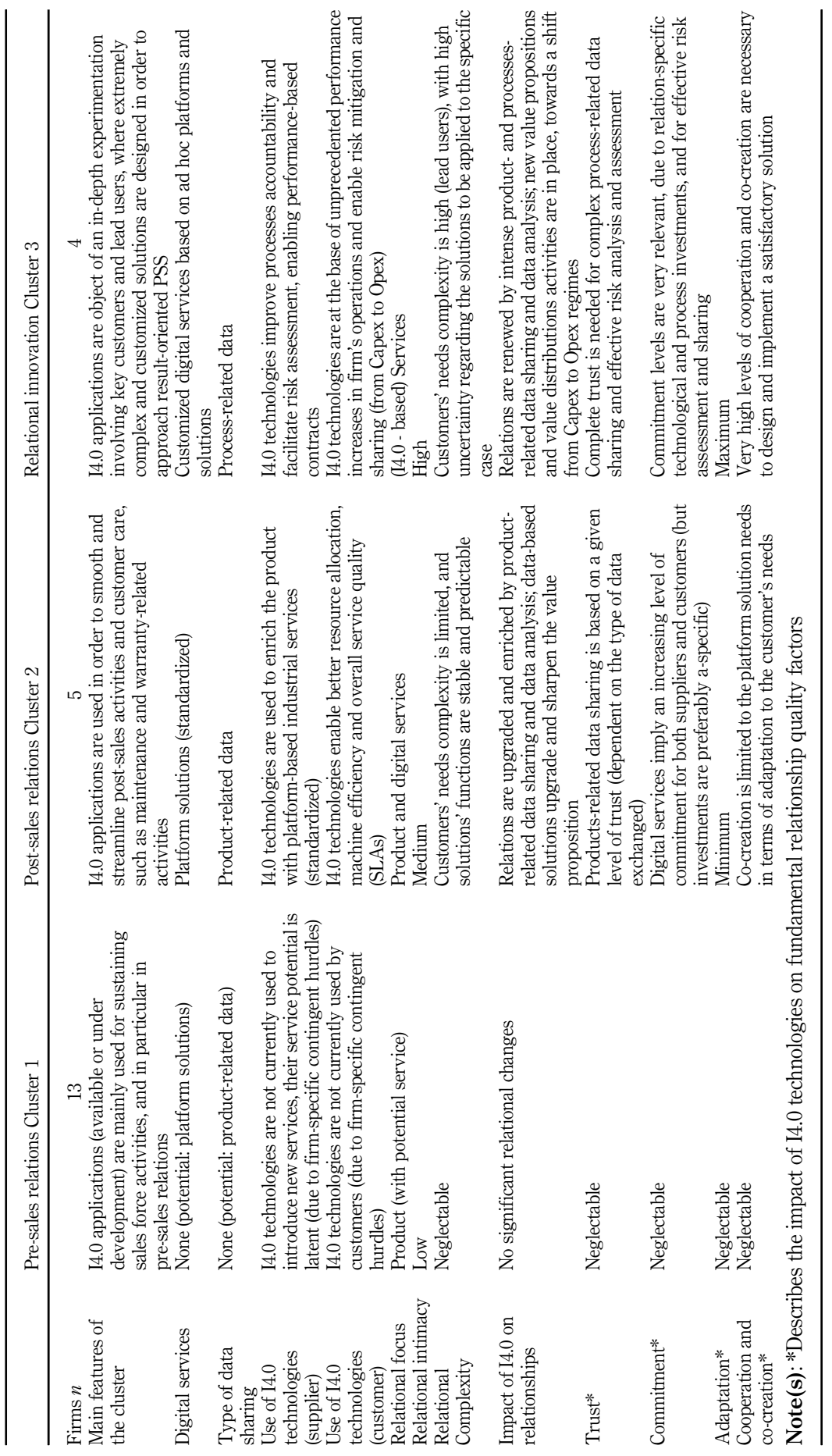


accordingly to what elsewhere has been associated to a "product-oriented service provider" business model (Kohtamäki et al., 2019): machines' connectivity (in view of an immediate or future use) is something that at the moment industrial customers are appreciating, also for the effects of tax advantages related to the new connectable capital expenditures (Capex). In this cluster, any effective use of technology to leverage data and innovate the relationship with customers is prevented by a poor relational quality: no co-creation activities are in fact activated by this cluster and all the data and information sharing that the technology would allow is a mere potentiality. Some specific and contingent hurdles, such as the position in the value chain, the complexity of downstream channels and the reaction of end-user firms, play an important role in this circumstance. This situation leads to a lack of coordination among and between the actors involved in the value system. At firm level, a product-centric model emerges in which provider-customer relationships are based on a transactional logic (Iansiti and Lakhani, 2014; Kohtamäki et al., 2019). Relational-specific factors such as information exchange, operational linkages, legal bonds, cooperative norms and buyer-supplier adaption are not integrated in the key business activities and negatively affect mutually value creation processes. In particular, being value delivery processes just confined in pre-sales services does not ensure that the value created is fully experienced by the customers. Then, in this situation moving towards a long-term relationship is fragile, featuring low levels of interdependence, relationship benefits, satisfaction and commitment (Palmatier et al., 2013). Drawing on these evidences, the following can be posited:

P1. "Product-oriented service provider" business models for I4.0-based servitization slightly affect the quality of relationship between suppliers and customers.

A second cluster composed by five firms is consciously focussing on using technology for streamlining traditional product life cycle service activities, with the aim of enriching the extant supplier-customer relationships on the base of data sharing, but not to subvert its current nature. This situation corresponds to what Kohtamäki et al. (2019) refer to as an "industrializer" servitization business model. A contractual relationship emerges in which post-sale services and customer care are the main focus of firms' strategies that actively and purposely design and deliver I4.0 solutions with the aim of reducing their post-sale services costs and the customers' total cost of ownership (TCO) at the same time. A particular trait separates this cluster from the preceding and following ones: here firms are supplying prevalently standard products, with good competitive positions in very articulated B2B value systems and are currently using Io T to consolidate their market relations, introducing digital services that are traditionally rooted in the product orientation of manufacturing firms. Firms are consciously taking into consideration the various scenarios that currently are available to them and decide to leverage on I4.0 without disrupting the favourable customer relations they currently have as the result of a consistent strategic decision. Anyway, to improve relational benefits, more commitment and adaptation are needed. Thus, a solution-based approach is embraced to ensure operational efficiency of providing a digitized solution to the customers (Green et al., 2017). It is against this backdrop that a functional co-creation takes place between suppliers and customers, with the aim of sharing information and analysing data with the specific aim of increasing the product's efficiency. Drawing on these evidences, the following can be posited:

P2. "Industrializer" business models for I4.0-based servitization reinforce the quality of relationship when suppliers and customers develop new digital services via functional co-creation.

Finally, an even more restricted cluster of firms (four in total) is engaged in I4.0-based servitization that is the result of a long and idiosyncratic cooperative relationship between the supplier and the customer, ending up in forging hardly substitutable suppliers and customers' 
TQM

32,4

666

relationships. This resembles the "outcome provider" and "customized integration solution provider" servitization business model (Kohtamäki et al., 2019).

In particular, this co-created servitization via I4.0 projects typically involves key customers. These are usually very large, sophisticated and culturally advanced firms facing global markets, often leaders in their respective industry. In these cases, using I4.0 technologies, firms are shifting from transactional to relationship-based interactions focussed on service-centred value propositions where value creation is outcome-based (i.e. better capability to achieve desired outcomes of technology) (Green et al., 2017). A mutual alignment entails close collaboration between the firm and the customer, also reducing information asymmetry and thereby enabling joint value creation ( $\mathrm{Ng}$ and Briscoe, 2012). Then, a substantial relational innovation is in place since the success of these innovative and complex solutions depends on the long-term commitment, adaptation, cooperation and ability of the all actors involved. Such relationships should be typical of those manufacturing companies using business models' solutions of customized integrated solution providers and outcome providers (Kohtamäki et al., 2019). These relationships are the background for complex co-creation processes based on the sharing of relevant operational and strategic knowledge, where an innovative value proposition is dynamically and collectively codesigned by suppliers and customers within their ecosystems. Drawing on these evidences, the following can be posited:

P3. "Customized integrated solution" and "outcome provider" business models for I4.0based servitization largely improve the quality of relationship when suppliers and customers are market leaders co-creating sophisticated PSSs.

\subsection{Theoretical and managerial implications}

Following the research line traced by the study, various theoretical and practical implications can be derived. Referring to theory, firstly this study contributes to the current mainstream servitization literature by exploring the mechanisms through which I4.0-based servitization improves relational quality adding novel knowledge in an under-researched topic in the servitization literature (Sjödin et al., 2016; Kamalaldin et al., 2020).

A second insight for scholars of I4.0-based servitization is that a successful and vigorous implementation of such phenomenon affects positively the quality of B2B relationships. However, this process is not always interesting or valid for all the manufacturing firms since, in some cases, they could prefer simpler and standardized PSSs and weaker relationships, requiring smaller investments of resources and risks. Therefore, scholars interested in cocreated servitization (Green et al., 2017) based on I4.0 technologies should consider to develop some specific frameworks or models useful to identify under which strategic, technological, organizational and environmental conditions it is better for supplier and customers to implement marginally, averagely or strongly such phenomenon.

Third, in relation to B2B theory, our study outlines how I4.0-based servitization affects the extent and nature of many typical elements of relationship quality (Athanasopoulou, 2009). This preliminary evidence stresses the need of exploring much more in detail how much each of these various elements is affected by I4.0-based servitization. Are there some specific configurations of IoT-based PSSs, for instance, that can affect and change power distribution or opportunistic behaviours among parties? Are there any ideal characteristics of the industrial partnership (e.g. low conflict and high commitment) able to maximize the outcomes of I4.0-based servitization for the involved actors? Answers to these and other complementary questions could greatly support manufacturing firms exploiting I4.0 technologies in ameliorating their industrial networks and reinforcing their position within them.

The study highlights also important implications for managers of $\mathrm{B} 2 \mathrm{~B}$ manufacturing firms willing to implement I4.0-based servitization. Firstly, the study shows that specific and 
sophisticated PSSs are not always the best solutions for satisfying customers and achieve competitive advantages. The investments of specific resources, the development of new technology-based value propositions and the revision of the corporate offering by suppliers may be appropriate only for some of their customers. Industrial managers, before offering digital servitization indistinctly, should properly analyse the specific needs of each customer and understanding which could be the partners more interested in, and potentially more benefiting from, specific and personalized PSSs. Conversely, the development of I4.0-based servitization not required (or not understood) by customers would lead the supplier to waste technological and financial resources and, in the end, to undermine the quality of their relationship. In other words, it is necessary to implement an evolutionary, long-period and proactive strategic approach by considering customers' needs and industry requirements change over time, in particular after the progressive introduction and implementation of I4.0 technologies at the industry level.

Second, the results clearly stress that industrial manufacturing companies willing to implement I4.0-based servitization cannot focus on just developing and expanding their technological capabilities. Since this process impacts on the various elements of relationship quality, these organizations should learn and develop also effective relational and collaborative skills in order to manage these socio-technical changes (Polese et al., 2011; Barnett et al., 2013). A suggested solution to develop such capabilities could be the arrangement of specific training and learning programmes for those internal employees unwilling to be relocated within the organization for implementing the activities linked to servitization. These programmes should attempt to develop both personal skills (e.g. communication styles) and professional knowledge (e.g. new contracting techniques). Such capabilities should be considered also when the company prefers to hire external ad-hoc human resources (e.g. data scientists, data analysts and business developers) for implementing and managing servitization.

\subsection{Limitations}

The present study does not come out without limitations due to its explorative nature. First, the present research did not analyse widely the large set of I4.0 technologies but just focussed on servitization and PSSs via IoT. However, I4.0-based servitization could be implemented also via other technological solutions, such as blockchain. This lack does not allow to understand if the technological variety of the fourth industrial revolution can impact in some way on the servitization approaches of industrial firms and the quality of their B2B relationships. Second, the sample of $\mathrm{B} 2 \mathrm{~B}$ manufacturing firms analysed represents only a portion, however relevant, of the industrial landscapes analysed. Other companies with different structural, organizational and market characteristics may develop different strategic and technological approaches for impacting in different manners on the quality of their industrial relationships. Further research on the relationships between I4.0 and the quality of customer-supplier relationships might address these limitations and, for instance, expand or update the proposed taxonomy.

\section{References}

Adrodegari, F. and Saccani, N. (2017), "Business models for the service transformation of industrial firms", The Service Industries Journal, Vol. 37 No. 1, pp. 57-83.

Arnold, K. and Voigt, K. (2016), "How the industrial internet of things changes business models in different manufacturing industries", International Journal of Innovation Management, Vol. 20 No. 8, p. 1640015.

Athanasopoulou, P. (2009), "Relationship quality: a critical literature review and research agenda", European Journal of Marketing, Vol. 43 Nos 5-6, pp. 583-610. 
TQM 32,4

Baines, T. (2015), "Exploring service innovation and the servitization of the manufacturing firm", Research-Technology Management, Vol. 58 No. 5, pp. 9-11.

Barnett, N., Parry, G., Saad, M., Newnes, L. and Goh, Y. (2013), "Servitization: is a paradigm shift in the business model and service enterprise required?”, Strategic Change, Vol. 22 Nos 3-4, pp. 145-156.

Bednarek, R., Burke, G., Jarzabkowski, P. and Smets, M. (2016), "Dynamic client portfolios as sources of ambidexterity: exploration and exploitation within and across client relationships", Long Range Planning, Vol. 49 No. 3, pp. 324-341.

Bustinza, O.F., Gomes, E., Vendrell-Herrero, F. and Tarba, S.Y. (2018), "An organizational change framework for digital servitization: evidence from the Veneto region”, Strategic Change, Vol. 27 No. 2, pp. 111-119.

Bustinza, O.F., Gomes, E., Vendrell-Herrero, F. and Baines, T. (2019), "Product-service innovation and performance: the role of collaborative partnerships and R\&D intensity", R\&D Management, Vol. 49 No. 1, pp. 33-45.

Coreynen, W., Matthyssens, P. and van Bockhaven, W. (2017), "Boosting servitization through digitization: pathways and dynamic resource configurations for manufacturers", Industrial Marketing Management, Vol. 60, pp. 42-53.

De Marchi, V. and Grandinetti, R. (2017), "Regional innovation systems or innovative regions? Evidence from Italy", Tijdschrift voor Economische en Sociale Geografie, Vol. 108 No. 2, pp. 234-249.

Ehret, M. and Wirtz, J. (2017), "Unlocking value from machines: business models and the industrial internet of things", Journal of Marketing Management, Vol. 33 Nos 1-2, pp. 111-130.

Eisenhardt, K.M. (1989), "Building theories from case study research", Academy of Management Review, Vol. 14 No. 4, pp. 532-550.

Frank, A.G., Mendes, G.H., Ayala, N.F. and Ghezzi, A. (2019), "Servitization and Industry 4.0 convergence in the digital transformation of product firms: a business model innovation perspective”, Technological Forecasting and Social Change, Vol. 141, pp. 341-351.

Gaiardelli, P., Resta, B., Martinez, V., Pinto, R. and Albores, P. (2014), "A classification model for product-service offerings", Journal of Cleaner Production, Vol. 66, pp. 507-519.

Green, M.H., Davies, P. and Ng, I.C. (2017), "Two strands of servitization: a thematic analysis of traditional and customer co-created servitization and future research directions", International Journal of Production Economics, Vol. 192, pp. 40-53.

Gunasekaran, A., Subramanian, N. and Ngai, W.T.E. (2019), "Quality management in the 21st century enterprises: research pathway towards Industry 4.0", International Journal of Production Economics, Vol. 207, pp. 125-129.

Huntley, J.K. (2006), "Conceptualization and measurement of relationship quality: linking relationship quality to actual sales and recommendation intention", Industrial Marketing Management, Vol. 35 No. 6, pp. 703-714.

Hypko, P., Tilebein, M. and Gleich, R. (2010), "Benefits and uncertainties of performance based contracting in manufacturing industries: an agency theory perspective", Journal of Service Management, Vol. 21 No. 4, pp. 460-489.

Iansiti, M. and Lakhani, K.R. (2014), "Digital ubiquity: how connections, sensors, and data are revolutionizing business", Harvard Business Review, Vol. 92 No. 11, p. 19.

Iansiti, M. and Lakhani, K.R. (2017), "The truth about blockchain”, Harvard Business Review, Vol. 95 No. 1, pp. 118-127.

Im, G. and Rai, A. (2008), "Knowledge sharing ambidexterity in long-term interorganizational relationships", Management Science, Vol. 54 No. 7, pp. 1281-1296.

Jiang, Z., Shiu, E., Henneberg, S. and Naude, P. (2016), "Relationship quality in business to business relationships. Reviewing the current literatures and proposing a new measurement model", Psychology and Marketing, Vol. 33 No. 4, pp. 297-313. 
Kamalaldin, A., Linde, L., Sjödin, D. and Parida, V. (2020), "Transforming provider-customer relationships in digital servitization: a relational view on digitalization", Industrial Marketing Management, pp. 1-20, doi: 10.1016/j.indmarman.2020.02.004.

Kamp, B. and Parry, G. (2017), "Servitization and advanced business services as levers for competitiveness", Industrial Marketing Management, Vol. 60, pp. 11-16.

Kindström, D. and Kowalkowski, C. (2014), "Service innovation in product-centric firms: a multidimensional business model perspective", Journal of Business and Industrial Marketing, Vol. 29 No. 2, pp. 96-111.

Kohtamäki, M., Parida, V., Oghazi, P., Gebauer, H. and Baines, T. (2019), "Digital servitization business models in ecosystems: a theory of the firm", Journal of Business Research, Vol. 104, pp. 380-392.

Kohtamäki, M., Parida, V., Patel, P.C. and Gebauer, H. (2020), "The relationship between digitalization and servitization: the role of servitization in capturing the financial potential of digitalization", Technological Forecasting and Social Change, Vol. 151, p. 119804.

Laudien, S.M. and Daxböck, B. (2016), "The influence of the industrial internet of things on business model design: a qualitative-empirical analysis", International Journal of Innovation Management, Vol. 20 No. 8, p. 1640014.

Li, Z., Wang, W.M., Liu, G., Liu, L., He, J. and Huang, G.Q. (2018), “Toward open manufacturing: a cross-enterprises knowledge and services exchange framework based on blockchain and edge computing", Industrial Management and Data Systems, Vol. 118 No. 1, pp. 303-320.

Liao, Y., Deschamps, F., Loures, E.D.F.R. and Ramos, L.F.P. (2017), "Past, present and future of Industry 4.0 - a systematic literature review and research agenda proposal", International Journal of Production Research, Vol. 55 No. 12, pp. 3609-3629.

Lo, F.Y. and Campos, N. (2018), "Blending Internet-of-Things (IoT) solutions into relationship marketing strategies", Technological Forecasting and Social Change, Vol. 137, pp. 10-18.

Martín-Peña, M.L., Díaz-Garrido, E. and Sánchez-López, J.M. (2018), "The digitalization and servitization of manufacturing: a review on digital business models", Strategic Change, Vol. 27 No. 2, pp. 91-99.

Martín-Peña, M., Sánchez-López, J. and Díaz-Garrido, E. (2020), "Servitization and digitalization in manufacturing: the influence on firm performance", Journal of Business and Industrial Marketing, Vol. 35 No. 3, pp. 564-574.

Matthyssens, P. (2019), "Reconceptualizing value innovation for industry 4.0 and the industrial internet of things", Journal of Business and Industrial Marketing, Vol. 34 No. 6, pp. 1203-1209.

Miles, M.B. and Huberman, A.M. (1994), Qualitative Data Analysis, Sage, Thousand Oaks.

Morgan, R.M. and Hunt, S.D. (1994), "The commitment-trust theory of relationship marketing”, Journal of Marketing, Vol. 58, pp. 20-38.

Müller, J.M., Buliga, O. and Voigt, K.I. (2018), "Fortune favors the prepared: how SMEs approach business model innovations in Industry 4.0", Technological Forecasting and Social Change, Vol. 132, pp. 2-17.

Ng, I.C.L. and Briscoe, G. (2012), "Value, variety and viability: new business models for co-creation in outcome-based contracts", International Journal of Service Science, Vol. 3 No. 3, pp. 26-48.

Paiola, M. and Gebauer, H. (2020), "Internet of things, digital servitization and business model innovation in BtoB manufacturing firms", Industrial Marketing Management, pp. 1-20, doi: 10. 1016/j.indmarman.2020.03.009.

Palmatier, R.W., Houston, M.B., Dant, R.P. and Grewal, D. (2013), "Relationship velocity: toward a theory of relationship dynamics", Journal of Marketing, Vol. 77 No. 1, pp. 13-30.

Polese, F., Pels, J. and Brodie, R.J. (2011), "Theoretical underpinning to successful value cocreation”, in Gummeson, E., Mele, C. and Polese, F. (Eds), The 2011 Naples Forum on Service - Service Dominant Logic, Network and Systems Theory and Service Science: Integrating Three Perspectives for a New Service Agenda, Giannini, Naples. 
TQM 32,4
Porter, M.E. and Heppelmann, J.E. (2014), "How smart connected products are transforming competition”, Harvard Business Review, Vol. 92 No. 11, pp. 65-88.

Ricciardi, F., Zardini, A. and Rossignoli, C. (2016), "Organizational dynamism and adaptive business model innovation: the triple paradox configuration", Journal of Business Research, Vol. 69 No. 11, pp. 5487-5493.

Rymaszewska, A., Helo, P. and Gunasekaran, A. (2017), "IoT powered servitization of manufacturing: an exploratory case study", International Journal of Production Economics, Vol. 192, pp. 92-105.

Santos, M.Y., Oliveira e Sá, J., Andrade, C., Vale Lima, F., Costa, C., Costa, E. and Galvão, J. (2017), "A big data system supporting Bosch Braga Industry 4.0 strategy", International Journal of Information Management, Vol. 37 No. 6, pp. 750-760.

Schmidt, C.G. and Wagner, S.M. (2019), "Blockchain and supply chain relations: a transaction cost theory perspective", Journal of Purchasing and Supply Management, Vol. 25 No. 4, p. 100552.

Sjödin, D., Parida, V. and Wincent, J. (2016), "Value co-creation process of integrated product-services: effect of role ambiguities and relational coping strategies", Industrial Marketing Management, Vol. 56, pp. 108-119.

Sklyar, A., Kowalkowski, C., Tronvoll, B. and Sörhammar, D. (2019), "Organizing for digital servitization: a service ecosystem perspective”, Journal of Business Research, Vol. 104, pp. 450-460.

Stake, R. (1995), The Art of Case Research, Sage, Thousand Oaks.

Storbacka, K., Strandvik, T. and Grönroos, C. (1994), "Managing customer relationships for profit: the dynamics of relationship quality", International Journal of Service Industry Management, Vol. 5 No. 5, pp. 21-38.

Ulaga, W. and Eggert, A. (2006), "Relationship value and relationship quality: broadening the nomological network of business-to-business relationships", European Journal of Marketing, Vol. 40 Nos 3-4, pp. 311-327.

Ulaga, W. and Reinartz, W.J. (2011), "Hybrid offerings: how manufacturing firms combine goods and services successfully", Journal of Marketing, Vol. 75 No. 6, pp. 5-23.

Vargo, S.L. and Lusch, R.F. (2008), "Service-dominant logic: continuing the evolution", Journal of the Academy of Marketing Science, Vol. 36 No. 1, pp. 1-10.

Vendrell-Herrero, F. and Wilson, J.R. (2017), "Servitization for territorial competitiveness: taxonomy and research agenda", Competitiveness Review, Vol. 27 No. 1, pp. 2-11.

Vendrell-Herrero, F., Bustinza, O.F., Parry, G. and Georgantzis, N. (2017) "Servitization, digitization and supply chain interdependency", Industrial Marketing Management, Vol. 60, pp. 69-81.

Voss, C., Tsikriktsis, N. and Frohlich, M. (2002), "Case research in operations management", International Journal of Operations and Production Management, Vol. 22 No. 2, pp. 195-219.

Yin, R.K. (1994), Case Study Research: Design and Methods, Sage, Thousand Oaks.

\section{Further reading}

Bastl, M., Johnson, M., Lightfoot, H. and Evans, S. (2012), "Buyer-supplier relationships in a servitized environment", International Journal Operation and Production Management, Vol. 32 No. 6, pp. $650-675$.

\section{Corresponding author}

Maria Vincenza Ciasullo can be contacted at: mciasullo@unisa.it 

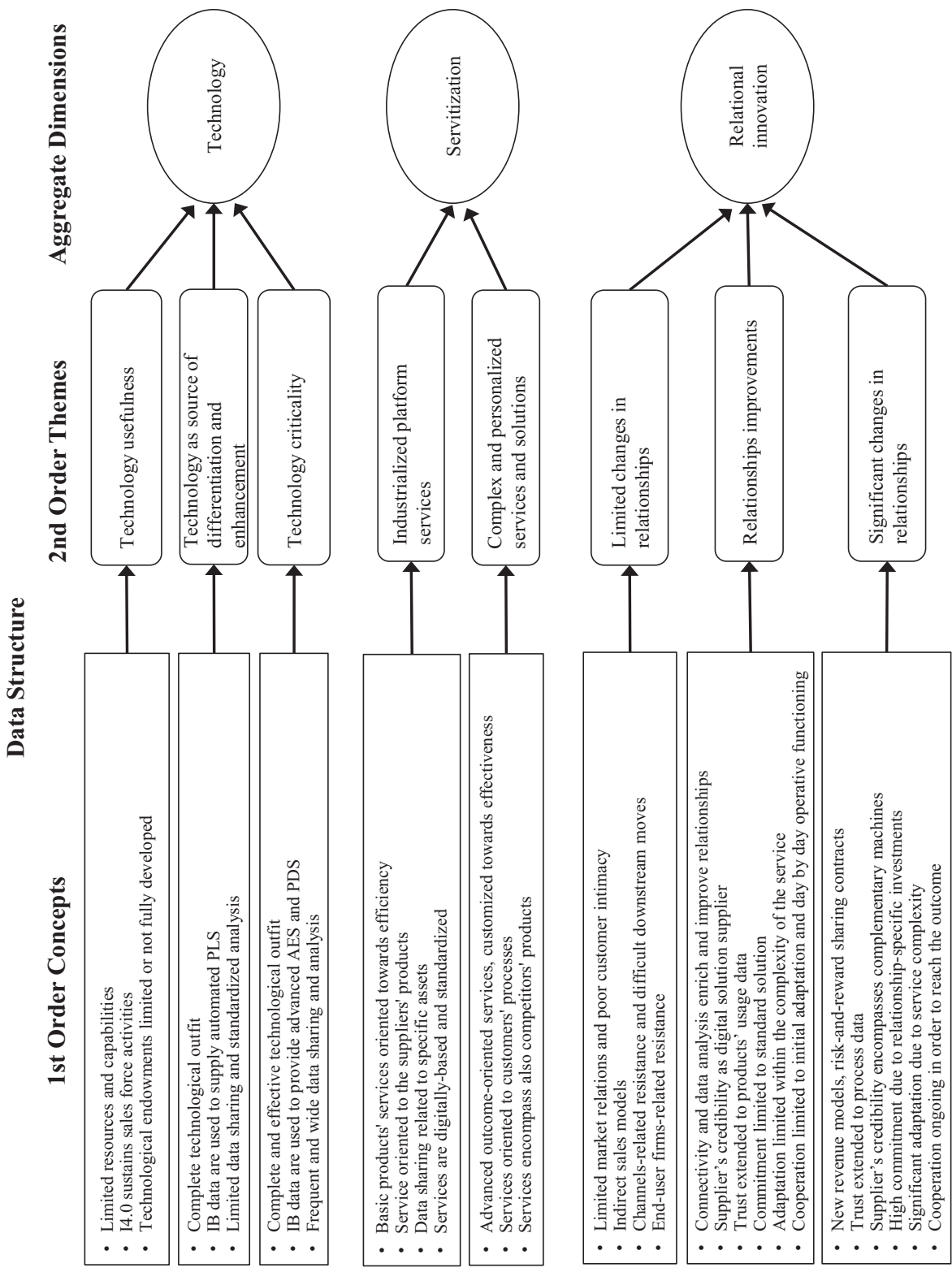